\title{
Modeling Heterogeneous Grades of Aggregate on Partial Replacement of Metakaolin on Compressive Strength of Concrete
}

\author{
Eluozo $\mathrm{SN}^{1 *}$ and Dimkpa $\mathrm{K}^{2}$ \\ ${ }^{1}$ Department of Civil Engineering, Gregory University Uturu (GUU), Nigeria \\ ${ }^{2}$ Department of Architecture, Rivers State University, Nigeria
}

*Corresponding author: Eluozo SN, Department of Civil Engineering, College of Engineering, Gregory University Uturu (GUU), Abia State of Nigeria, Nigeria

\begin{abstract}
Aggregate in different size has been known to be one of the concrete properties in strength development of any grades. The study evaluates the sizes of aggregate in heterogeneous condition to determine their various rate of effect to the optimum required strength. These are determined on the design grade required based on the imposed loads evenly distributed, the study precisely monitored the impact of heterogeneity of aggregate size at different mixed proportion, the size and shapes of aggregate were considered in the study integrated with Metakaolin content at different dosage, the study observed linear growth to the optimum level recorded at twenty eight days of curing, various predictive values were generated to monitor the variationof developed strength influenced by heterogeneous aggregate size, it is observed that the larger the size, the lower surface for the development of the gel bonds, these were monitored and evaluated based on the developed modeling techniques, other observation shows that the bigger size of aggregate on heterogeneous level inconcrete mix prevent the uniformity of load distribution,when it experience stress. Compactions of the concrete were other parameter that displayed its effect on the variation of strength as it experienced the effect on this condition, while others include the cement-aggregate ratios and curing time. The predictive values were compared with experimental data for model validation, and both parameters developed best fits correlation, the study is imperative because the effect of aggregate size and shapes has be evaluated, there rate of impact on concrete strength partially replaced with Metakaolin has been determined.
\end{abstract}

Keywords: Modeling heterogeneous, Aggregate Metakaolin and compressive strength

\section{Introduction}

The pursue for high strength by experts to monitor the growth rate of high-performance concretes has definitely improved substantially in this current time; it has been observed that there high demands for high performance concrete nearly all construction industries. It has observed in the these last three decades, the level integration of cementitious materials, these includes such as fly ash, silica fume and ground granulated blast furnace slag, such modifiers are currently integrated fully, this materials are applied as partial cement replacement materials, more so studies has expressed it clearly that it has experienced meaningfully improvement on the strength and stability characteristics of concrete, comparing it with ordinary Portland cement (OPC) alone. Such examination has definitely provided adequate required curing [1-4]. More so in this current state of scientific approach, there is need for high strength concrete, addictive such as silica fume has been observed to be more useful [5,6].These types of additive's have created serious impact developed good particle packing based on its level of strong pozzolanic property, this implies that it has escalated the resistance of concrete in these aggressive environments, more so Metakaolin (MK) according to [7,8]. Furthermore, materials such as calcined kaolin, and other type of pozzolan, these materials are generated from calcinations; it has the capability to be applied as substitute 
silica fume material. In nation like India MK has generated a very elevated measure of quantities, these are procedures of generating kaolin mineral, these concepts are very wide spread that has proven it reserves availability in most nations [9-13]. Previously, numerous studies have shown high rate of interest in MK, because it has been observed to possess both pozzolanic and microfiller as its characteristics [4,13-15]. Such application has proven successfully development of high strength, including self-compacting concrete applying mathematical modeling [16,17].

\section{Theoretical Background}

$$
\frac{d_{c d}}{d x}+V(y) c_{d}=\varnothing(y) c_{d}^{n}
$$

Dividing equation (1.0) all through by $c_{d}^{n}$ we have

$$
\begin{aligned}
& \text { Let } \begin{array}{l}
c_{d}^{-n} \frac{d_{c d}}{d x}+v(x) c_{c}^{1-n}=\varnothing(y) \\
p=c_{d}^{1-n} \\
\qquad \frac{d p}{d y}=(1-n) c_{d}^{1-n} \frac{d_{c d}}{d y} \\
c_{d}^{-n} \frac{d_{c d}}{d y}=\frac{1}{1-n} \frac{d p}{d y}
\end{array}
\end{aligned}
$$

Substituting equation (1.2) and (1.3) into equation (1.1) we have that

$$
\frac{1}{1-n} \frac{d p}{d x}+V(y) p=\varnothing(y)
$$

Integrating both sides we have $\int d\left[e^{V(y)(1-n) y} p\right]=\varnothing(y)(1-n) \int e^{V(1-n) y} d y$

$$
p=\frac{\varnothing(y)}{v u(y)}+A e^{-v u(y)(1-n) y}
$$

Substituting equation (1.2) into equation (1.13) we have

$$
c_{d}^{1-n}=\frac{\varnothing(y)}{v u(y)}+A e^{-V u(y)(1-n) y}
$$

\section{Materials and Method}

\section{Experimental procedures}

Compressive Strength Test Concrete cubes of size $150 \mathrm{~mm} \times 150 \mathrm{~mm} \times 150 \mathrm{~mm}$ were cast with and without copper slag. During casting, the cubes were mechanically vibrated using a table vibrator. After 24 hours, the specimens were demoulded and subjected to curing for 1-90 days and seven-day interval to 28 days in portable water. After curing, the specimens were tested for compressive strength using compression testing machine of 2000KN capacity. The maximum load at failure was taken. The average compressive strength of concrete and mortar specimens was calculated by using the following equation

$$
\text { Compressive strength }\left(\mathrm{N} / \mathrm{mm}^{2}\right)=\text { Ultimate compressive load }
$$

Area of cross section of specimen $\left(\mathrm{mm}^{2}\right)$

\section{Results and Discussion}

Table 1-7; Figures 1-7. The figures explained the behaviour of the gravel size and shape on the bond from variations of compressive strength at different water cement ratios and curing age. The trend at different figures experienced linear increase to optimum level recorded at twenty eight day of curing, but the compressive observed at different figures experienced the expected variation of strength that determined the effect of heterogeneous aggregate size, because decrease of the strength was experienced at different figures, even though linear trend was observed in all the figures, the impact of the heterogeneity on the concrete shows that larger maximum size aggregate gives lower surface area for developments of gel bonds, this is responsible for the lower strength of the concrete. Secondly bigger aggregate size causes a more heterogeneity in the concrete which will prevent the uniform distribution of load when stressed. The behaviour of the model concrete on Metakaolin as partial replacement for cement experience similar condition, but the developed model concrete grades are high strength, the study observed the effect from the aggregate heterogeneity impact on variation of compressive strength, but still maintained the influenced from the heterogeneous impact in all the figures. The predictive values in figure seven and eight explained the variation of water cement ratios against curing age, the graphical expression shows the rates of decrease in strength as the water cement ratios increase, such experience were determined in the study, numerical simulation shows results expected of the material based on the behaviour of the compressive strength, these experimental values for model validation maintained similar trend expressing best fit correlations.

Table 1: Predictive and experimental values of compressive strength at different curing age.

\begin{tabular}{|c|c|c|}
\hline Curing age & Predictive values of compressive strength [W/C 0.40] & Experimental values of compressive strength [W/C 0.40] \\
\hline 7 & 29.47561688 & 27.628 \\
\hline 8 & 31.29773568 & 29.472 \\
\hline 9 & 33.11985448 & 31.316 \\
\hline 10 & 34.94197328 & 33.16 \\
\hline 11 & 36.76409208 & 35.004 \\
\hline
\end{tabular}




\begin{tabular}{|l|l|c|}
\hline 12 & 38.58621088 & 36.848 \\
\hline 13 & 40.40832968 & 38.692 \\
\hline 14 & 42.23044849 & 40.536 \\
\hline 15 & 44.05256729 & 42.38 \\
\hline 16 & 45.87468609 & 44.224 \\
\hline 17 & 47.69680489 & 46.068 \\
\hline 18 & 49.51892369 & 47.912 \\
\hline 19 & 51.34104249 & 49.756 \\
\hline 20 & 53.16316129 & 51.6 \\
\hline 21 & 54.98528009 & 53.444 \\
\hline 22 & 56.80739889 & 55.288 \\
\hline 23 & 58.62951769 & 57.132 \\
\hline 24 & 60.45163649 & 58.976 \\
\hline 25 & 62.27375529 & 60.82 \\
\hline 26 & 64.09587409 & 62.664 \\
\hline 27 & 65.91799289 & 64.508 \\
\hline 28 & 67.74011169 & 66.352 \\
\hline
\end{tabular}

Table 2: Predictive and experimental values of compressive strength at different curing age.

\begin{tabular}{|c|c|c|}
\hline Curing age & Predictive values of compressive strength [W/C 0.44] & Experimental values of compressive strength [W/C 0.44] \\
\hline 7 & 28.97549278 & 27.4 \\
\hline 8 & 30.72616528 & 29.04 \\
\hline 9 & 32.47683778 & 30.68 \\
\hline 10 & 34.22751028 & 32.32 \\
\hline 11 & 35.97818278 & 33.96 \\
\hline 12 & 37.72885528 & 35.6 \\
\hline 13 & 39.47952778 & 37.24 \\
\hline 14 & 41.23020028 & 38.88 \\
\hline 15 & 42.98087278 & 40.52 \\
\hline 16 & 44.73154528 & 42.16 \\
\hline 17 & 46.48221778 & 43.8 \\
\hline 18 & 48.23289029 & 45.44 \\
\hline 19 & 49.98356279 & 47.08 \\
\hline 20 & 51.73423529 & 48.72 \\
\hline 21 & 53.48490779 & 50.36 \\
\hline 22 & 55.23558029 & 52 \\
\hline 23 & 56.98625279 & 53.64 \\
\hline 24 & 58.73692529 & 55.28 \\
\hline 25 & 60.48759779 & 56.92 \\
\hline 26 & 62.23827029 & 58.56 \\
\hline 27 & 63.98894279 & 60.2 \\
\hline 28 & 65.73961529 & 61.84 \\
\hline
\end{tabular}


Table 3: Predictive and experimental values of compressive strength at different curing age.

\begin{tabular}{|c|c|c|}
\hline Curing age & Predictive values of compressive strength [W/C 0.46] & Experimental values of compressive strength[W/C 0.46] \\
\hline 7 & 28.73283332 & 27.42 \\
\hline 8 & 30.44884018 & 29.12 \\
\hline 9 & 32.16484704 & 30.82 \\
\hline 10 & 33.8808539 & 32.52 \\
\hline 11 & 35.59686076 & 34.22 \\
\hline 12 & 37.31286763 & 35.92 \\
\hline 13 & 39.02887449 & 37.62 \\
\hline 14 & 40.74488135 & 39.32 \\
\hline 15 & 42.46088821 & 41.02 \\
\hline 16 & 44.17689507 & 42.72 \\
\hline 17 & 45.89290194 & 44.42 \\
\hline 18 & 47.6089088 & 46.12 \\
\hline 19 & 49.32491566 & 47.82 \\
\hline 20 & 51.04092252 & 49.52 \\
\hline 21 & 52.75692939 & 51.22 \\
\hline 22 & 54.47293625 & 52.92 \\
\hline 23 & 56.18894311 & 54.62 \\
\hline 24 & 57.90494997 & 56.32 \\
\hline 25 & 59.62095683 & 58.02 \\
\hline 26 & 61.3369637 & 59.72 \\
\hline 27 & 63.05297056 & 61.42 \\
\hline 28 & 64.76897742 & 63.12 \\
\hline
\end{tabular}

Table 4: Predictive and experimental values of compressive strength at different curing age.

\begin{tabular}{|c|c|c|}
\hline Curing age & Predictivevalues ofcompressive strength [W/C 0.48] & Experimental values of compressive strength[W/C 0.48] \\
\hline 7 & 28.49497883 & 26.48 \\
\hline 8 & 30.17700648 & 28.06 \\
\hline 9 & 31.85903413 & 29.64 \\
\hline 10 & 33.54106178 & 31.22 \\
\hline 11 & 35.22308943 & 32.8 \\
\hline 12 & 36.90511708 & 34.38 \\
\hline 13 & 38.58714473 & 35.96 \\
\hline 14 & 40.26917238 & 37.54 \\
\hline 15 & 41.95120003 & 39.12 \\
\hline 16 & 43.63322767 & 40.7 \\
\hline 17 & 45.31525532 & 42.28 \\
\hline 18 & 46.99728297 & 43.86 \\
\hline 19 & 48.67931062 & 45.44 \\
\hline 20 & 50.36133827 & 47.02 \\
\hline 21 & 52.04336592 & 48.6 \\
\hline 22 & 53.72539357 & 50.18 \\
\hline 23 & 55.40742122 & 51.76 \\
\hline 24 & 57.08944887 & 53.34 \\
\hline 25 & 58.77147652 & 54.92 \\
\hline 26 & 60.45350417 & 56.5 \\
\hline
\end{tabular}




\begin{tabular}{|l|l|l|}
\hline 27 & 62.13553182 & 58.08 \\
\hline 28 & 63.81755947 & 59.66 \\
\hline
\end{tabular}

Table 5: Predictive and experimental values of compressive strength at different curing age.

\begin{tabular}{|c|c|c|}
\hline Curing age & Predictivevalues ofcompressive strength [W/C 0.49] & Experimental values of compressive strength [W/C 0.49] \\
\hline 7 & 28.37782364 & 26.55 \\
\hline 8 & 30.04311484 & 28.14 \\
\hline 9 & 31.70840603 & 29.73 \\
\hline 10 & 33.37369723 & 31.32 \\
\hline 11 & 35.03898842 & 32.91 \\
\hline 12 & 36.70427962 & 34.5 \\
\hline 13 & 38.36957081 & 36.09 \\
\hline 14 & 40.03486201 & 37.68 \\
\hline 15 & 41.7001532 & 39.27 \\
\hline 16 & 43.3654444 & 40.86 \\
\hline 17 & 45.03073559 & 42.45 \\
\hline 18 & 46.69602679 & 44.04 \\
\hline 19 & 48.36131798 & 45.63 \\
\hline 20 & 50.02660918 & 47.22 \\
\hline 21 & 51.69190037 & 48.81 \\
\hline 22 & 53.35719157 & 50.4 \\
\hline 23 & 55.02248276 & 51.99 \\
\hline 24 & 56.68777396 & 53.58 \\
\hline 25 & 58.35306515 & 55.17 \\
\hline 26 & 60.01835635 & 56.76 \\
\hline 27 & 61.68364754 & 58.35 \\
\hline 28 & 63.34893874 & 59.94 \\
\hline
\end{tabular}

Table 6: Variation of water cement ratios on experimental values of compressive strength at different curing age.

\begin{tabular}{|c|c|c|c|c|c|}
\hline Variation ofW/C]on experimental values ofcompressive strength & 0.4 & 0.44 & 0.46 & 0.48 & 0.49 \\
\hline $7 \mathrm{fcu}$ & 27.628 & 27.4 & 27.42 & 26.48 & 26.55 \\
\hline $8 \mathrm{fcu}$ & 29.472 & 29.04 & 29.12 & 28.06 & 28.14 \\
\hline $9 \mathrm{fcu}$ & 31.316 & 30.68 & 30.82 & 29.64 & 29.73 \\
\hline $10 \mathrm{fcu}$ & 33.16 & 32.32 & 32.52 & 31.22 & 31.32 \\
\hline $11 \mathrm{fcu}$ & 35.004 & 33.96 & 34.22 & 32.8 & 32.91 \\
\hline $12 \mathrm{fcu}$ & 36.848 & 35.6 & 35.92 & 34.38 & 34.5 \\
\hline $13 \mathrm{fcu}$ & 38.692 & 37.24 & 37.62 & 35.96 & 36.09 \\
\hline $14 \mathrm{fcu}$ & 40.536 & 38.88 & 39.32 & 37.54 & 37.68 \\
\hline $15 \mathrm{fcu}$ & 42.38 & 40.52 & 41.02 & 39.12 & 39.27 \\
\hline $16 \mathrm{fcu}$ & 44.224 & 42.16 & 42.72 & 40.7 & 40.86 \\
\hline $17 \mathrm{fcu}$ & 46.068 & 43.8 & 44.42 & 42.28 & 42.45 \\
\hline $18 \mathrm{fcu}$ & 47.912 & 45.44 & 46.12 & 43.86 & 44.04 \\
\hline $19 \mathrm{fcu}$ & 49.756 & 47.08 & 47.82 & 45.44 & 45.63 \\
\hline $20 \mathrm{fcu}$ & 51.6 & 48.72 & 49.52 & 47.02 & 47.22 \\
\hline $21 \mathrm{fcu}$ & 53.444 & 50.36 & 51.22 & 48.6 & 48.81 \\
\hline $22 \mathrm{fcu}$ & 55.288 & 52 & 52.92 & 50.18 & 50.4 \\
\hline $23 \mathrm{fcu}$ & 57.132 & 53.64 & 54.62 & 51.76 & 51.99 \\
\hline $24 \mathrm{fcu}$ & 58.976 & 55.28 & 56.32 & 53.34 & 53.58 \\
\hline
\end{tabular}




\begin{tabular}{|c|c|c|c|c|c|}
\hline $25 \mathrm{fcu}$ & 60.82 & 56.92 & 58.02 & 54.92 & 55.17 \\
\hline $26 \mathrm{fcu}$ & 62.664 & 58.56 & 59.72 & 56.5 & 56.76 \\
\hline $27 \mathrm{fcu}$ & 64.508 & 60.2 & 61.42 & 58.08 & 58.35 \\
\hline $28 \mathrm{fcu}$ & 66.352 & 61.84 & 63.12 & 59.66 & 59.94 \\
\hline
\end{tabular}

Table 7: Variation of water cement ratios on experimental values of compressive strength at different curing age.

\begin{tabular}{|c|c|c|c|c|c|}
\hline Variation of $[\mathrm{W} / \mathrm{C}]$ on predictive values of compressive strength & 0.4 & 0.44 & 0.46 & 0.48 & 0.49 \\
\hline $7 \mathrm{fcu}$ & 29.47562 & 28.97549 & 28.73283 & 28.49498 & 28.37782 \\
\hline $8 \mathrm{fcu}$ & 31.29774 & 30.72617 & 30.44884 & 30.17701 & 30.04311 \\
\hline $9 \mathrm{fcu}$ & 33.11985 & 32.47684 & 32.16485 & 31.85903 & 31.70841 \\
\hline $10 \mathrm{fcu}$ & 34.94197 & 34.22751 & 33.88085 & 33.54106 & 33.3737 \\
\hline $11 \mathrm{fcu}$ & 36.76409 & 35.97818 & 35.59686 & 35.22309 & 35.03899 \\
\hline $12 \mathrm{fcu}$ & 38.58621 & 37.72886 & 37.31287 & 36.90512 & 36.70428 \\
\hline $13 \mathrm{fcu}$ & 40.40833 & 39.47953 & 39.02887 & 38.58714 & 38.36957 \\
\hline $14 \mathrm{fcu}$ & 42.23045 & 41.2302 & 40.74488 & 40.26917 & 40.03486 \\
\hline $15 \mathrm{fcu}$ & 44.05257 & 42.98087 & 42.46089 & 41.9512 & 41.70015 \\
\hline $16 \mathrm{fcu}$ & 45.87469 & 44.73155 & 44.1769 & 43.63323 & 43.36544 \\
\hline $17 \mathrm{fcu}$ & 47.6968 & 46.48222 & 45.8929 & 45.31526 & 45.03074 \\
\hline $18 \mathrm{fcu}$ & 49.51892 & 48.23289 & 47.60891 & 46.99728 & 46.69603 \\
\hline $19 \mathrm{fcu}$ & 51.34104 & 49.98356 & 49.32492 & 48.67931 & 48.36132 \\
\hline $20 \mathrm{fcu}$ & 53.16316 & 51.73424 & 51.04092 & 50.36134 & 50.02661 \\
\hline $21 \mathrm{fcu}$ & 54.98528 & 53.48491 & 52.75693 & 52.04337 & 51.6919 \\
\hline $22 \mathrm{fcu}$ & 56.8074 & 55.23558 & 54.47294 & 53.72539 & 53.35719 \\
\hline $23 \mathrm{fcu}$ & 58.62952 & 56.98625 & 56.18894 & 55.40742 & 55.02248 \\
\hline $24 \mathrm{fcu}$ & 60.45164 & 58.73693 & 57.90495 & 57.08945 & 56.68777 \\
\hline $25 \mathrm{fcu}$ & 62.27376 & 60.4876 & 59.62096 & 58.77148 & 58.35307 \\
\hline $26 \mathrm{fcu}$ & 64.09587 & 62.23827 & 61.33696 & 60.4535 & 60.01836 \\
\hline $27 \mathrm{fcu}$ & 65.91799 & 63.98894 & 63.05297 & 62.13553 & 61.68365 \\
\hline $28 \mathrm{fcu}$ & 67.74011 & 65.73962 & 64.76898 & 63.81756 & 63.34894 \\
\hline
\end{tabular}

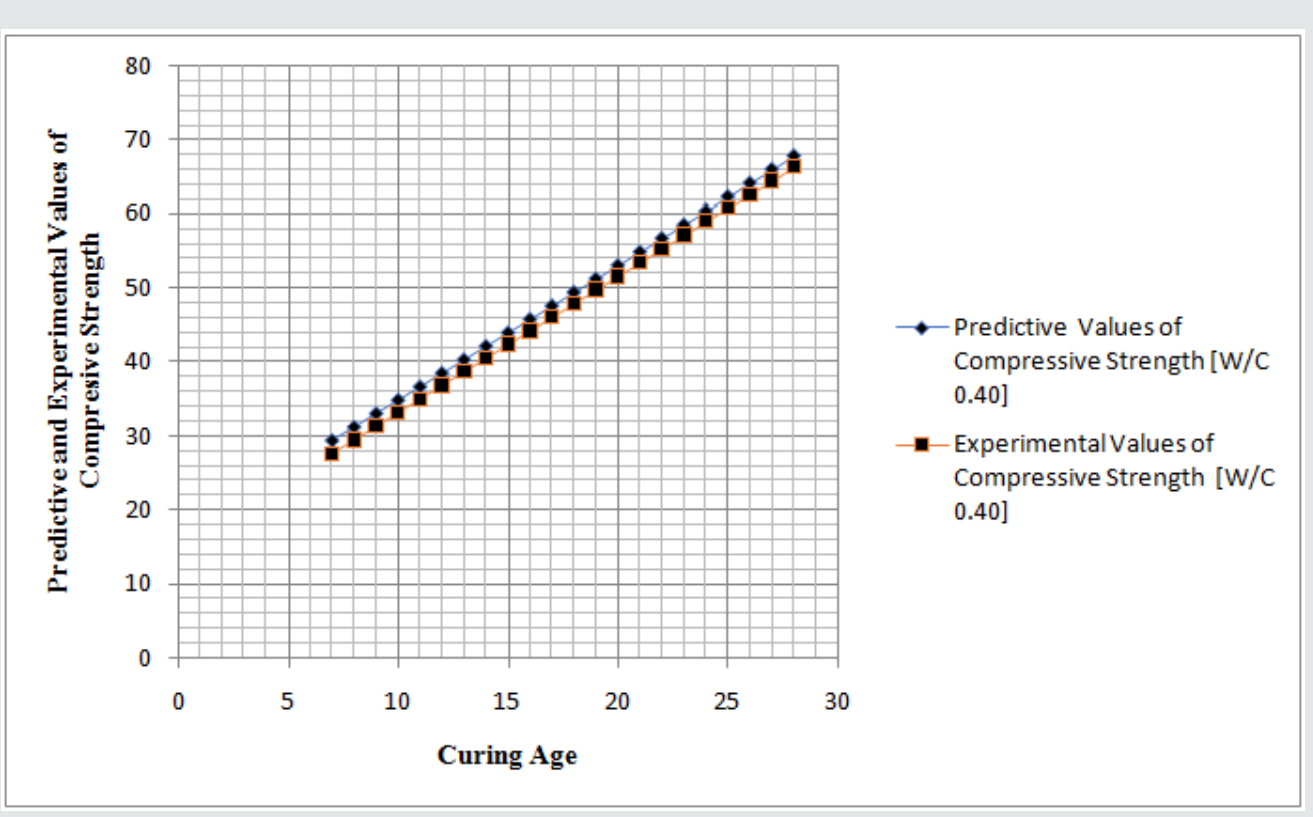

Figure 1: Predictive and Experimental Values of Compressive Strength at Different Curing Age. 


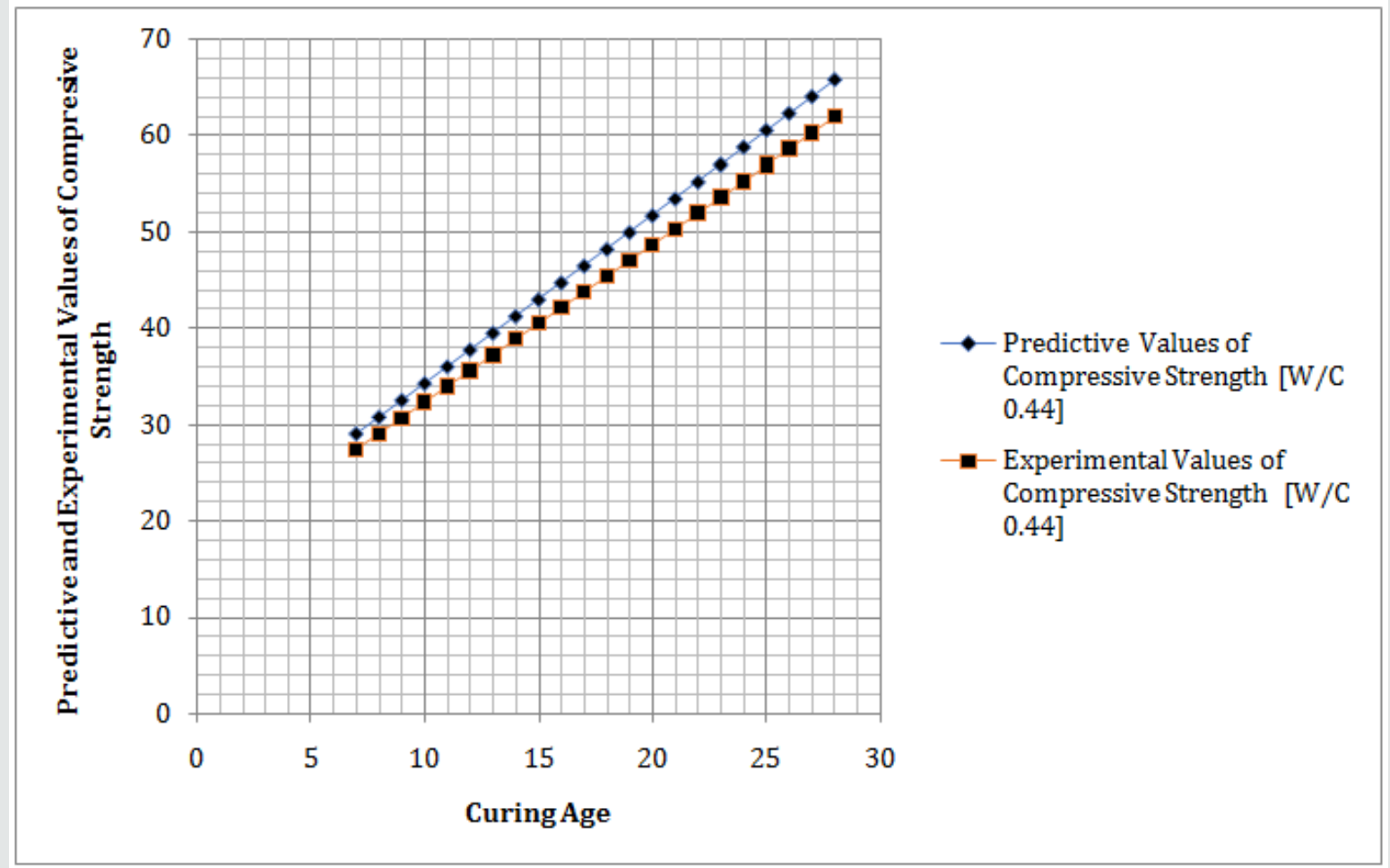

Figure 2: Predictive and Experimental Values of Compressive Strength at Different Curing Age.

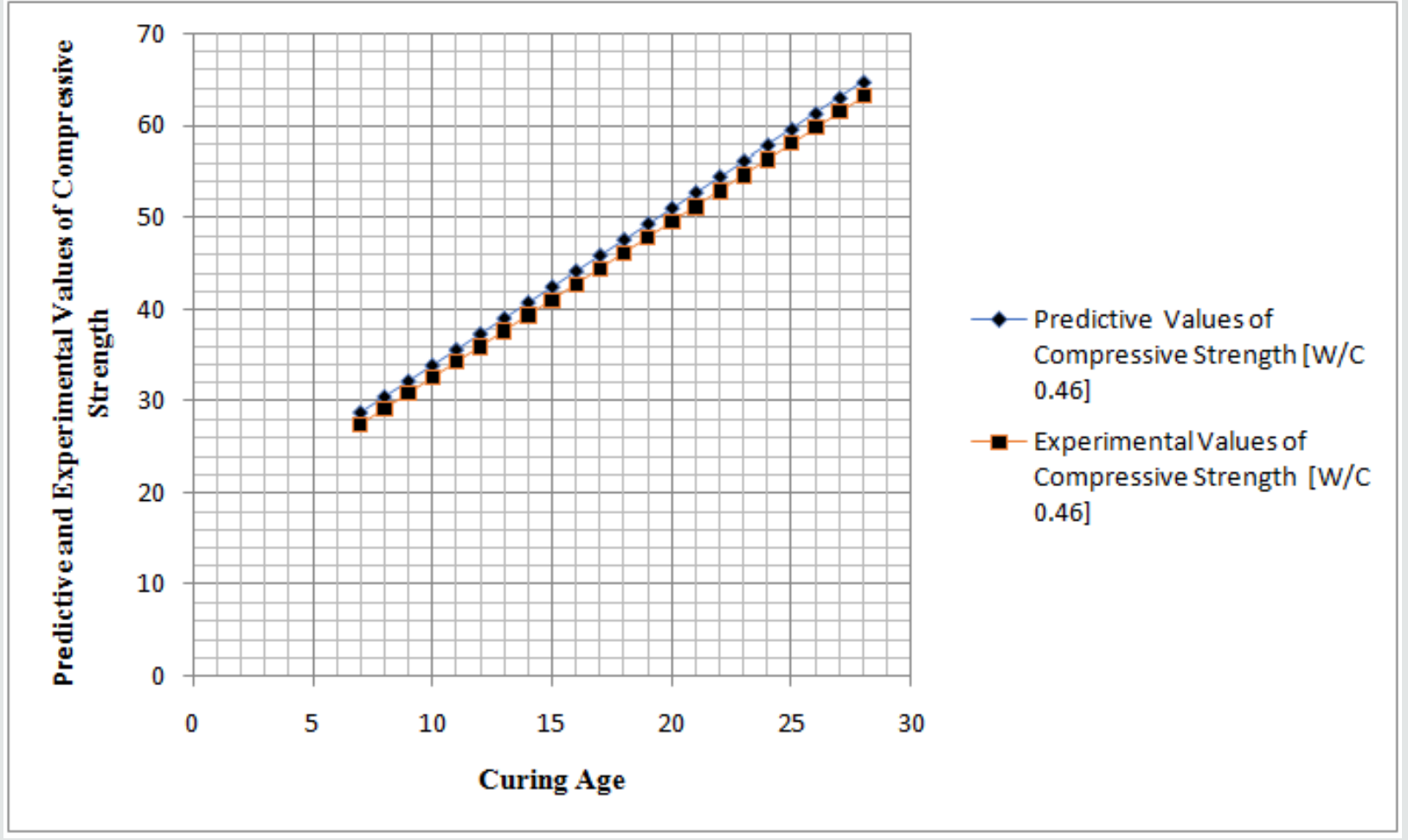

Figure 3: Predictive and Experimental Values of Compressive Strength at Different Curing Age 


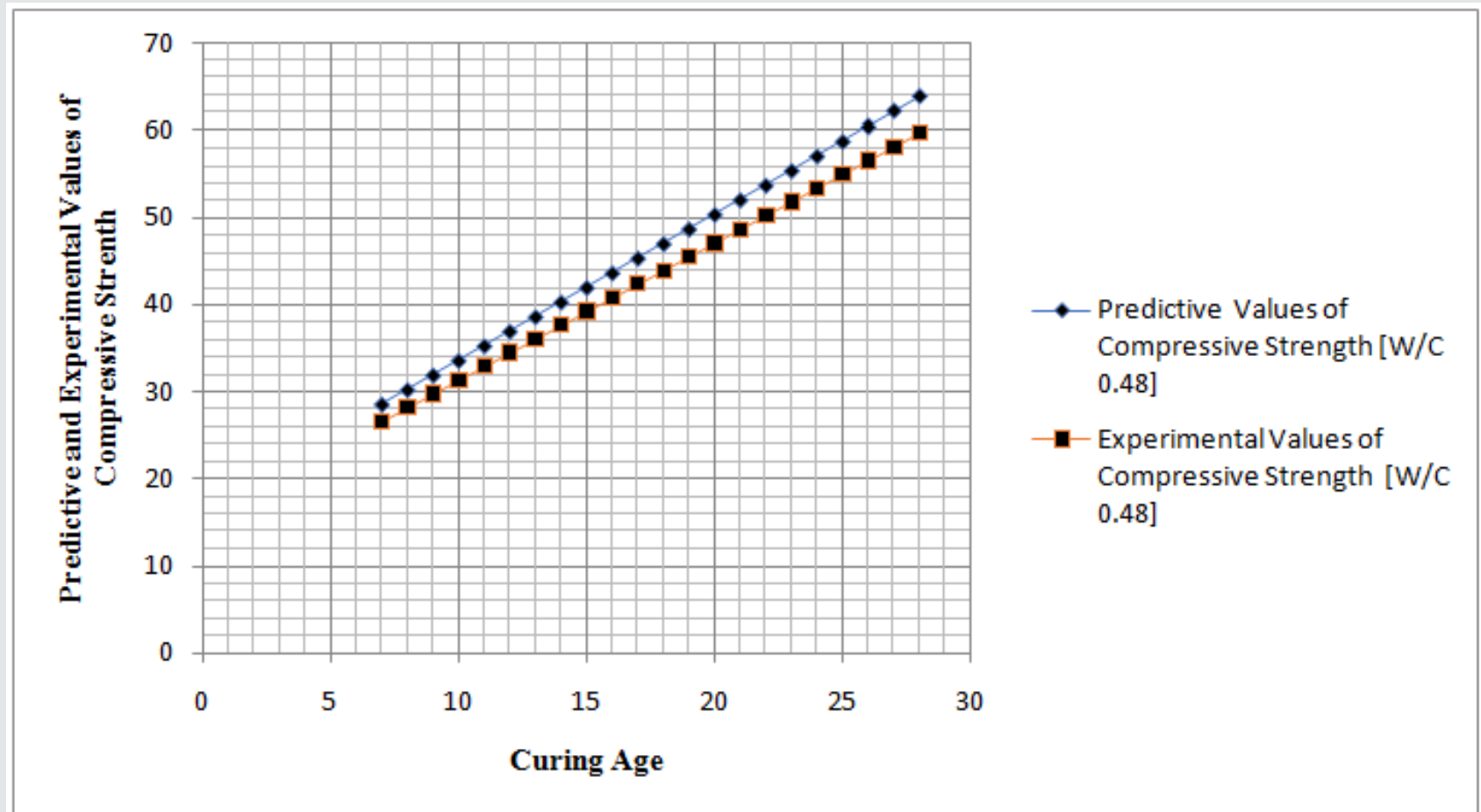

Figure 4: Predictive and Experimental Values of Compressive Strength at Different Curing Age.

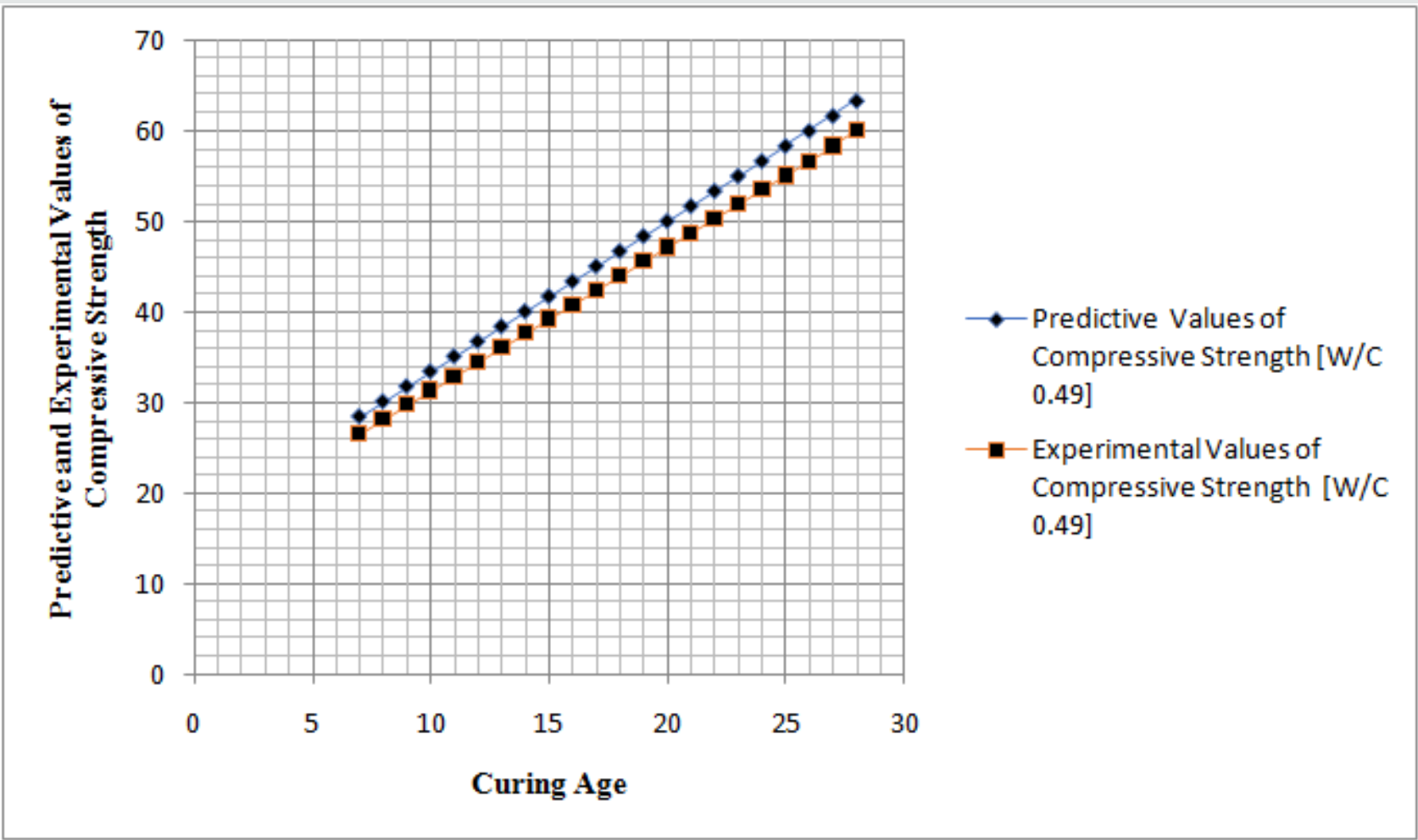

Figure 5: Predictive and Experimental Values of Compressive Strength at Different Curing Age. 


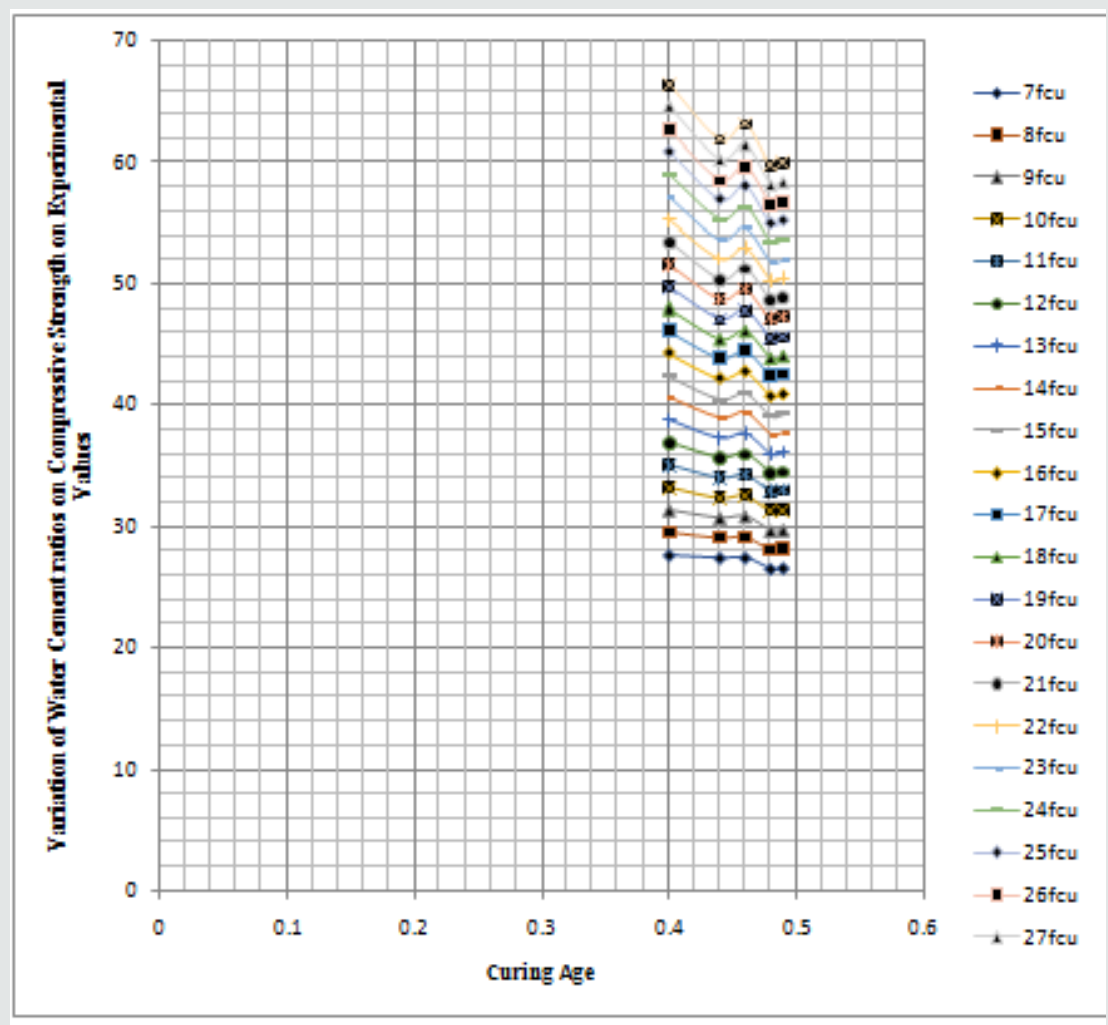

Figure 6: Variation of Water Cement Ratios on Experimental Values of Compressive Strength at Different Curing Age.

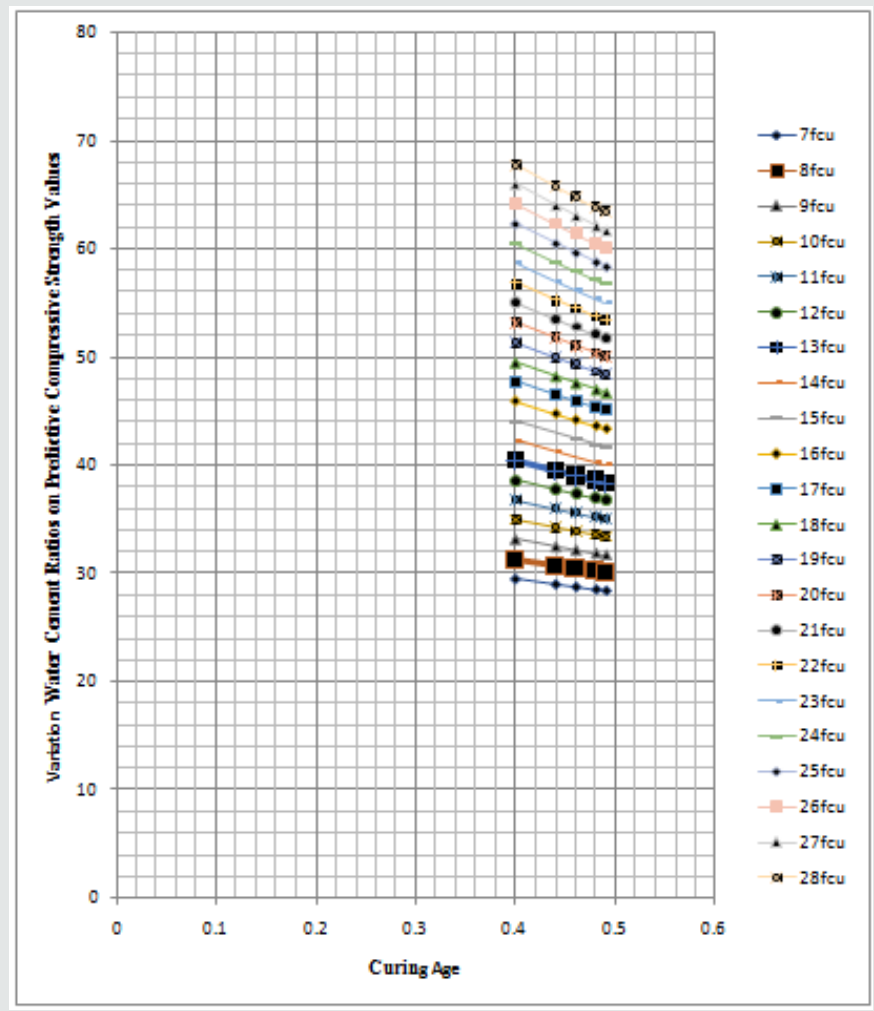

Figure 7: Variation of Water Cement Ratios on Predictive Values of Compressive Strength at Different Curing Age. 


\section{Conclusion}

The study monitors the behaviour of Metakaolin content as partial replacement on strength development influence by heterogeneous aggregate within curing age of $[18,19]$. Mixed design of concrete grades were carried out integrating Metakaolin content to monitor the behaviour of the material in terms of its bond compared to other addictives, but the major study carried out were to monitor the variation of strength development from heterogeneity of aggregate since, it is one of concrete properties. Metakaolin substance partially replaced cement that react with the concrete properties to generate these strength at different curing time, the study expressed graphically in linear trend at various water mixed ratios proportions, but the strength development were observed to vary compared to different mixed proportion, aggregate as concrete property were influenced on the mixed design to monitor the effect of strength growth, this were observed based on the shapes and variation of size, the application of this concrete property were experienced to determine its rate of effect on concrete strength development from variation of aggregate size. It is observed that the larger the size, the lower the surface for the development of the gel bonds, these were monitored and it was observed that the lower strength of concrete were experienced based on the effect of the aggregate heterogeneous size, other observation shows that the bigger size of aggregate on heterogeneous level in concrete mix prevent the uniformity of load distribution, when it experience stress. Compactions of the concrete were other parameter that displayed its effect on the variation of strength development, while other includes the cement-aggregate ratio and curing time. The application of modeling and simulations express details on the other parameters that played roles in the variations of concrete strength, Metakaolin as partial replacement expressed it strength as expected on its rate as a parameter, but the aggregate size at different grades in mixed design were the detail and precise study were carried out, the variations are influenced on the strength development that has been determined.

\section{References}

1. Neville AM (1997) Concrete with particular properties in Properties of concrete. Harlow, UK: Longmanpp. 653-672.

2. Ode T, Eluozo SN (2016) Predictive Model on Compressive Strength of Concrete Made with Locally 3/8 Gravel from Different Water Cement Ratios and Curing Age.International Journal of Scientific and Engineering Research 7(1): pp1528-1551.

3. Ode T, Eluozo SN (2016) Model Prediction to Monitorthe Rate of Water Absorption of Concrete Pressured by Variation of Time and Water Cement Ratios. International Journal of Scientific and Engineering Research 7(1): 1514-1527.
4. Karthika PA, Gayathri V (2018)Experimental studies on durability aspects of high strength concrete using flyash and Alccofine. International Journal of Recent Technology and Engineering (IJRTE) 7 (4S): 423-427.

5. Basu P C (2003) High performance concrete. In Proceedings INAE national seminar on engineered building materials and their performance pp. 426-450.

6. Ode T, Eluozo SN (2016) Calibrating the Density of Concrete from Washed and Unwashed Locally 3/8 Gravel Material at Various Curing Age. International Journal of Scientific and Engineering Research7(1): 1514-1552-15574.

7. OdeT, Eluozo SN (2016)Compressive Strength Calibration of Washed and Unwashed Locally Occurring3/8 Gravel from Various Water Cement Ratios and Curing Age. International Journal Engineering and General Science 4(1): 462-483.

8. Abdul RH, Wong HS (2005) Strength estimation model for high-strength concrete incorporating Metakaolin and silica fume. Cement Concrete Research 35(4): 688-695.

9. Ode T, Eluozo SN (2016) Predictive Model to Monitor Variation of Concrete Density Influenced by Various Grade from Locally 3/8 Gravel at Different Curing Time. International Journal Engineering and General Science 4(1): 502-522.

10. Basu PC, Mavinkurve S, Bhattacharjee KN, Deshpande Y, Basu S (2000) High reactivity metakaolin: A supplementary cementitious material. In Proceedings ICIAsian conference on ecstasy in concrete 20-22 Nov Bangalore India pp. 237-436.

11. Tiwari AK, Bandyopadhyay P (2003) High performance concrete with Indian Metakaolin. In International symposium on innovative world of concrete 19-21 September. Pune: Indian Concrete Institute.

12. Ode T, Eluozo SN (2016) Predictive Modelto Monitor Vitiation of StressStrain Relationship of 3/8 Gravel Concrete with Water Cement Ration [0.45] at Different Load.International Journal Engineering and General Science 4(1): 409-418.

13. Poon CS, Lam L, Kou SC, Wong YL, Wong R(2001) Rate of pozzolanic reaction of metakaolin in high-performance cement pastes. Cement and Concrete Research 31(9): 1301-1306.

14. Wild S, KhatibJM (1997) Portlandite consumption of Metakaolin cements Pastes and mortars. Cement and Concrete Research 27(1): 137-146.

15. Wild S, Khatib JM, Jones A (1996) Relative strength, pozzolanic activity and cement hydration in superplasticiser Metakaolin concrete. Cement and Concrete Research26(10): 1537-1544.

16. Pal SC, Mukherjee A, Pathak SR (2001) Development of high performance concrete composites using high volume cement replacement with supplementary pozzolanic and [8] cementitious solid waste In: SK Kaushik (Edt.), Proceedings of SEC, recent developments in structural engineering, New Delhi, India: Phoenix publishing house Pvt Ltd, pp. 215-229.

17. Patil BB, Kumbhar PD (2012) Strength and durability properties of high-performance concrete incorporating high reactivity Metakaolin. International Journal of Modern Engineering Research 2(3): 1099-1104.

18. Dinakar P (2012) Design of self-compacting concrete with flyash Magazine of Concrete Research 64(5):401-409.

19. P Dinakar, Pradosh K Sahoo, G Sriram (2013) Effect of Metakaolin Content on the Properties of High StrengthConcrete International Journal of Concrete Structures and Materials7(3) pp.215-223. 
This work is licensed under Creative Commons Attribution 4.0 License

To Submit Your Article Click Here: Submit Article

DOI: $10.32474 /$ TCEIA.2020.04.000179

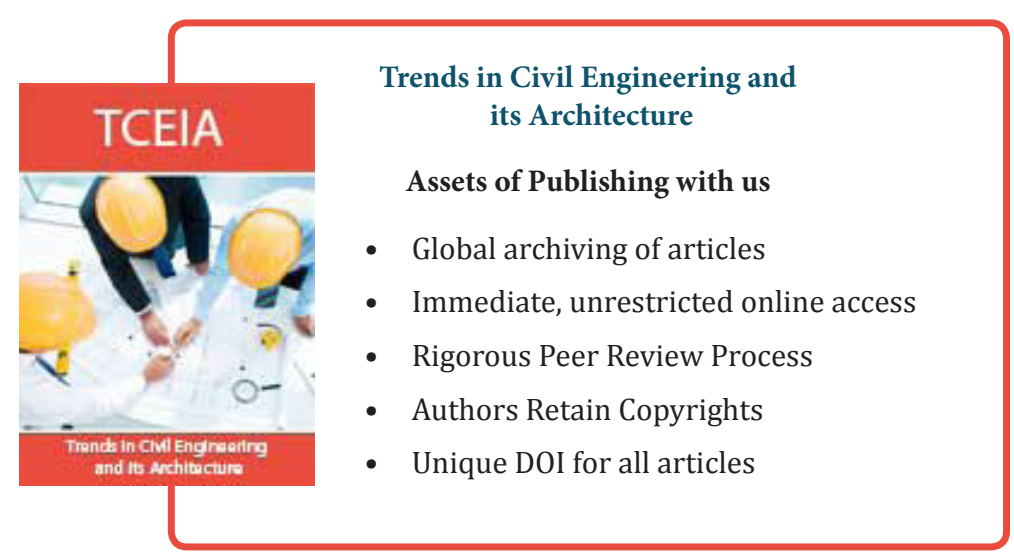

